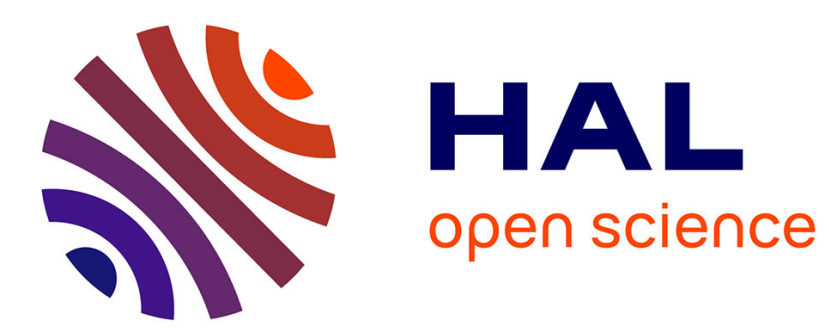

\title{
Assessment of the refined sinus model for the non-linear analysis of composite beams
}

\author{
P. Vidal, O. Polit
}

\section{To cite this version:}

P. Vidal, O. Polit. Assessment of the refined sinus model for the non-linear analysis of composite beams. Composite Structures, 2009, 87 (4), pp.370-381. 10.1016/j.compstruct.2008.02.007 . hal01366935

\section{HAL Id: hal-01366935 \\ https://hal.science/hal-01366935}

Submitted on 8 Jan 2018

HAL is a multi-disciplinary open access archive for the deposit and dissemination of scientific research documents, whether they are published or not. The documents may come from teaching and research institutions in France or abroad, or from public or private research centers.
L'archive ouverte pluridisciplinaire HAL, est destinée au dépôt et à la diffusion de documents scientifiques de niveau recherche, publiés ou non, émanant des établissements d'enseignement et de recherche français ou étrangers, des laboratoires publics ou privés. 


\title{
Assessment of the refined sinus model for the non-linear analysis of composite beams
}

\author{
P. Vidal, O. Polit* \\ LMpX, Universite' Paris X-Nanterre, 50 rue de Se vres, 92410 Ville d'Avray, France
}

\begin{abstract}
The objective of this paper is to evaluate a new three-noded mechanical beam finite element for the non-linear analysis of laminated beams. It is based on a sinus distribution with layer refinement. The transverse shear strain is obtained by using a cosine function avoiding the use of shear correction factors. This kinematic accounts for the interlaminar continuity conditions on the interfaces between layers, and the boundary conditions on the upper and lower surfaces of the beam. A conforming FE approach is carried out using Lagrange and Hermite interpolations. It is important to notice that the number of unknowns is independent from the number of layers.

Buckling, post-buckling, and non-linear bending tests are presented in order to compare with the ones available in the literature or based on a 2D analysis. The influence of mesh, boundary conditions, length-to-thickness ratios and lay-ups is studied to show the accuracy and the efficiency of this finite element.
\end{abstract}

Keywords: Laminated composite beam; Geometric non-linearity; Higher-order transverse shear; Layer refinement; Finite element

\section{Introduction}

Composite and sandwich structures are widely used in the engineering field due to their excellent mechanical properties. In this context, they can be submitted to severe conditions. For composite design, accurate knowledge of deflection or stresses is required to take into account effects of transverse shear deformation due to the low ratio of transverse shear modulus to axial modulus, or failure due to delamination ... In fact, they can play an important role on the behaviour of structures in services, which leads to evaluate precisely their influence on stresses, particularly on the interface of layers.

The aim of this paper is to evaluate a new finite element introduced in [2] which allows to analyze laminated composite beams. This particular study focuses on elasticity field in relation to moderately large displacements.

\footnotetext{
* Corresponding author. Fax: +331470952 24.

E-mail address: philippe.vidal@u-paris10.fr (O. Polit).
}

According to published research, various theories in mechanics for composite or sandwich structures have been developed. They can be classified as:

- The equivalent single layer (ESL): the number of unknowns is independent from the number of layers, but the shear stress continuity on the interfaces of layers are often violated. We can distinguish the classical laminate theory [3] (it is based on the Euler-Bernoulli hypothesis and leads to inaccurate results for composites and moderately thick beams, because the transverse shear is neglected), the first-order shear deformation theory, and higher-order theories: [4-12] which analyse stresses for beams and plates. These theories are also applied to buckling problems. A finite element model is developed in [13]. A parabolic distribution is chosen in [1]. Karama [14,15] uses an exponential function for in-plane displacement components. In [16], the method of power series expansion of displacement components is carried out. We also find works about stepped composite beams [17]. And, in [18], the displacement 
components are expressed in a series of simple algebraic polynomials with the Ritz method to obtain the critical buckling load. Concerning non-linear bending analyses, Chandrashekhara [19] and Polit [20] develop a finite element approach.

- The discrete layer theory or layer-wise approach (DLT): this theory aims at overcoming the restriction of the ESL about the discontinuity of in-plane displacement on the interface layers [21-24] (FSDT), [25]. Few works about buckling problems are applied to beams.In this framework, some authors have developed the zigzag model in order to improve the accuracy of results and reduce the number of unknowns for multilayered composites. This model has the advantage of taking into account the first derivative discontinuity of the in-plane displacement in the transverse direction. This was first employed by Murakami [26] with Reissner's new mixed variational principle to develop a plate theory. Then, it was also used and improved by Reddy, Icardi, Di Sciuva, Averill, Cho, Carrera [27-32], with different order kinematics assumptions. For a review of zig-zag method, see Carrera [33]. In the context of buckling analyses, see [34].

A multitude of analysis models for layered structures and corresponding finite element formulations have been developed over many years. An extensive assessment of different approaches has been made by Noor [35], Reddy [36] and Carrera [37]. Overviews about the particular problem of buckling of composite plate and shell structures are given in [38].

Thus, the proposed finite element which belongs to a family of sinus models for rectangular laminated beam analysis is built, in order to have a low cost tool, efficient and simple to use. In fact, our approach is associated with the ESL theory. This element is totally free of shear locking and is based on a refined shear deformation theory [39] avoiding the use of shear correction factors for laminates. Our element is based on the sinus model [40]. It is $\mathrm{C}^{0}$-continuous except for the transverse displacement associated with bending which is $\mathrm{C}^{1}$. It should be noted that all the interface and boundary conditions are exactly satisfied for displacements and stresses. Therefore, this approach takes into account physical meaning. The new model named SinRef-c model uses a Heaviside function to satisfy conditions of continuity. It is based on the double superposition hypothesis from [41]. Three local functions are added to the sinus model. It yields to only four independent generalized displacements, i.e. three displacements and one rotation.

In this article, first the mechanical formulation for the refined sinus model is described. The associated finite element is given in the context of the geometric non-linearity. It is illustrated by numerical tests which have been performed upon various laminated beams.

In particular, the influence of boundary conditions and stacking sequences on critical buckling loads is investigated as in [18]. A parametric study is given to show the effects of different parameters such as length-to-thickness ratio and number of degrees of freedom. The accuracy of computations are also evaluated by comparisons with literature results and also two-dimensional finite element computations using commercial codes.

Finally, other numerical examples are presented to demonstrate the effectiveness and the accuracy of the finite element models for post-buckling and non-linear analyses. Computations for different stacking sequences are compared to 2D finite element computations.

\section{Resolution of the mechanical problem}

\subsection{The governing equations for mechanics}

Let us consider a beam occupying the domain $\mathcal{B}=[0, L] \times\left[-\frac{h}{2} \leqslant z \leqslant \frac{h}{2}\right] \times\left[-\frac{b}{2} \leqslant x_{2} \leqslant \frac{b}{2}\right]$ in a cartesian coordinate $\left(x_{1}, x_{2}, z\right)$. The beam has a rectangular uniform cross-section of height $h$, width $b$ and is assumed to be straight. The beam is made of NC layers of different linearly elastic materials. Each layer may be assumed to be transversely isotropic in the beam axes. The $x_{1}$ axis is taken along the central line of the beam whereas $x_{2}$ and $z$ are the two axes of symmetry of the cross-section intersecting at the centroïd, see Fig. 1. As shown in this figure, the $x_{2}$ axis is along the width of the beam. This work is based upon a displacement approach for geometrically non-linear elastic beams. The list of principal notations is listed in Table 1.

\subsubsection{Constitutive relation}

Using matrix notations, the one-dimensional constitutive equations of an orthotropic material are given by:

$\left[\begin{array}{c}\sigma_{11} \\ \sigma_{13}\end{array}\right]=\left[\begin{array}{cc}\bar{C}_{11} & 0 \\ 0 & \bar{C}_{55}\end{array}\right]\left[\begin{array}{l}\varepsilon_{11} \\ \varepsilon_{13}\end{array}\right] \quad$ i.e. $[\sigma]=[\bar{C}][\varepsilon]$

where we denote: the stress tensor $[\sigma]$; the strain tensor $[\varepsilon]$. Furthermore, in Eq. (1), constitutive unidimensional laws are given by the elastic stiffness tensor $[\bar{C}]$.

Taking into account the classic assumption $\sigma_{22}=\sigma_{33}=0$ (transverse normal stresses are negligible), the longitudinal modulus is expressed from the three dimensional constitutive laws by:

$\bar{C}_{11}=C_{11}-2 C_{12}^{2} /\left(C_{23}+C_{33}\right)$

where $C_{i j}$ are orthotropic three-dimensional elastic moduli. We also have $\bar{C}_{55}=C_{55}$.

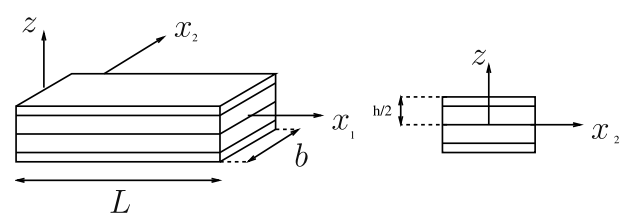

Fig. 1. The laminated beam and co-ordinate system. 
Table 1

Principal notations

\begin{tabular}{ll}
\hline$[\sigma]$ & Stress tensor \\
{$[\varepsilon]$} & Strain tensor \\
{$\left[\varepsilon_{\mathrm{L}}\right]$} & Linear part of strain tensor \\
{$\left[\varepsilon_{\mathrm{NL}}\right]$} & Non-linear part of strain tensor \\
$C_{i j}$ & 3D elastic stiffness modulus \\
$\bar{C}_{i j}$ & 1D elastic stiffness modulus \\
{$\left[K_{e}\right]$} & Elementary stiffness matrix \\
{$\left[K_{\mathrm{T} e}\right]$} & Elementary tangent stiffness matrix \\
{$\left[\mathcal{E}_{u}\right],\left[\mathcal{E}_{s}\right]$} & Generalized displacement vector \\
{$[N],[B]$} & Interpolation functions vector and derivatives vector \\
{$\left[q_{e}\right]$} & Degrees of freedom elementary vector \\
$\vec{u}$ & Displacement vector \\
$L$ & Length of the beam \\
$b$ & Width of the beam \\
$h$ & Height of the beam \\
$\mathrm{NC}$ & Number of layers \\
$N$ & Number of elements \\
$t$ & Time \\
$S$ & Length to thickness ratio \\
$\alpha_{k}$ & Continuity coefficient for the Sin-c model \\
$\left(\delta_{i}^{k}, \beta_{i}^{k}\right)_{i=1,2,3}$ & Continuity coefficients for the SinRef-c model \\
$\mathrm{SinRef}-\mathrm{c}$ & Refined sinus model with continuity requirements \\
\hline &
\end{tabular}

\subsubsection{The weak form of the boundary value problem}

Using the above matrix notations and for admissible virtual displacement $\vec{u}^{*} \in U^{*}$, the variational principle is given by:

Find $\vec{u} \in U$ (space of admissible displacements) such as:

$J\left(\vec{u}, \vec{u}^{*}\right)_{\mathcal{B}}=a\left(\vec{u}, \vec{u}^{*}\right)_{\mathcal{B}}-f\left(\vec{u}^{*}\right)_{\mathcal{B}}-F\left(\vec{u}^{*}\right)_{\partial \mathcal{B}_{F}}=0, \quad \forall \vec{u}^{*}$

with

$$
\begin{aligned}
& a\left(\vec{u}, \vec{u}^{*}\right)_{\mathcal{B}}=\int_{\mathcal{B}}\left[\varepsilon\left(\vec{u}^{*}\right)\right]^{\mathrm{T}}[\sigma(\vec{u})] \mathrm{d} \mathcal{B} \\
& f\left(\vec{u}^{*}\right)_{\mathcal{B}}=\int_{\mathcal{B}}\left[\vec{u}^{*}\right]^{\mathrm{T}}[f] \mathrm{d} \mathcal{B} \\
& F\left(\vec{u}^{*}\right)_{\partial \mathcal{B}_{F}}=\int_{\partial \mathcal{B}_{F}}\left[\vec{u}^{*}\right]^{\mathrm{T}}[F] \mathrm{d} \partial \mathcal{B}
\end{aligned}
$$

where $[f]$ and $[F]$ are the prescribed body and surface forces applied on $\partial \mathcal{B}_{F} \cdot \varepsilon\left(\vec{u}^{*}\right)$ is the virtual strain.

Eq. (3) is a classical starting point for finite element approximations.

\subsection{The displacement field for laminated beams: the refined sinus model}

Based on the sinus function (see $[42,43]$ ), the refined sinus model denoted SinRef-c is presented in this section.

This part is based on both:

- various works on beams, plates and shells, cf. Refs. $[20,39,40,42,44,45]$ concerning the refined theory,

- the so-called 1-3 double-superposition theory developed by Li and Liu [41].

It also follows works about local-global approach studied in $[46,47]$.
The SinRef-c model (see [2]) takes into account the continuity conditions between layers of the laminate for both displacements and transverse shear stress, and the free conditions on the upper and lower surfaces owing to the heaviside function. Moreover, the refinement is added in each layer.

Hence, in our approach, the displacement field is assumed to be of the following particular form (with $\left.w^{\prime}=\partial w / \partial x_{1}\right)$ :

$$
\left\{\begin{aligned}
u_{1}\left(x_{1}, x_{2}, z, t\right)= & u\left(x_{1}, t\right)-z w\left(x_{1}, t\right)^{\prime} \\
& +f(z)\left(\omega_{3}\left(x_{1}, t\right)+w\left(x_{1}, t\right)^{\prime}\right)+\sum_{k=1}^{\mathrm{NC}}\left(\bar{u}_{\mathrm{loc}}^{(k)}\left(x_{1}, z, t\right)\right. \\
& \left.+\hat{u}_{\mathrm{loc}}^{(k)}\left(x_{1}, z, t\right)\right)\left(H\left(z-z_{k}\right)-H\left(z-z_{k+1}\right)\right) \\
u_{3}\left(x_{1}, x_{2}, z, t\right)= & w\left(x_{1}, t\right)
\end{aligned}\right.
$$

where $H$ is the Heaviside function defined by

$$
\left\{\begin{array}{l}
H\left(z-z_{k}\right)=1 \text { if } z \geqslant z_{k} \\
H\left(z-z_{k}\right)=0 \text { if not }
\end{array}\right.
$$

$t$ is the time and $\zeta_{k}=a_{k} z-b_{k}, a_{k}=\frac{2}{z_{k+1}-z_{k}}, b_{k}=\frac{z_{k+1}+z_{k}}{z_{k+1}-z_{k}}$.

In the context of the sinus model, we have:

$f(z)=\frac{h}{\pi} \sin \frac{\pi z}{h}$

and this function will represent the transverse shear strain distribution due to bending by its derivative.

The local functions $\bar{u}_{\mathrm{loc}}^{(k)}$ and $\hat{u}_{\mathrm{loc}}^{(k)}$ based on the Legendre polynomial can be written as:

$$
\left\{\begin{array}{l}
\bar{u}_{\mathrm{loc}}^{(k)}\left(x_{1}, z, t\right)=\zeta_{k} u_{31}^{k}\left(x_{1}, t\right)+\left(-\frac{1}{2}+\frac{3 \zeta_{k}^{2}}{2}\right) u_{32}^{k}\left(x_{1}, t\right) \\
\hat{u}_{\mathrm{loc}}^{(k)}\left(x_{1}, z, t\right)=\left(-\frac{3 \zeta_{k}}{2}+\frac{5 \zeta_{k}^{3}}{2}\right) u_{33}^{k}\left(x_{1}, t\right)
\end{array}\right.
$$

In the classic approach, $w$ is bending deflection following the $z$ direction. $u$ is associated with the uniform extension of the cross-section of the beam along the central line. And, $\omega_{3}$ is the shear bending rotation around the $z$ axis.

Remarks:

- From Eq. (5), classical beam models can be deduced without the local functions:

- Euler-Bernoulli

$$
f(z)=0
$$

- Timoshenko

$$
f(z)=z
$$

- sinus model

$$
f(z)=\frac{h}{\pi} \sin \frac{\pi z}{h}
$$

- These Legendre polynomials have the interesting following properties: if we note $A_{1}=\zeta_{k}, A_{2}=-\frac{1}{2}+\frac{3 \zeta_{k}^{2}}{2}$ and $A_{3}=-\frac{3 \zeta_{k}}{2}+\frac{5 \zeta_{k}^{3}}{2}$ 


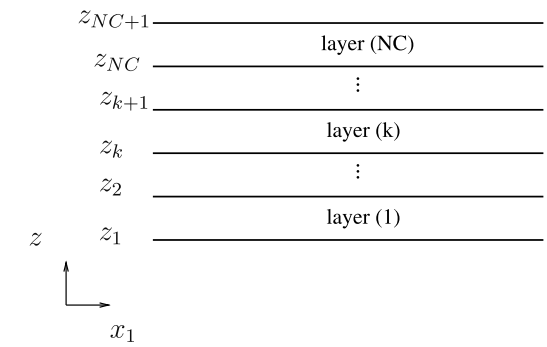

Fig. 2. Coordinate system of laminated beam.

$\int_{-1}^{+1} A_{i} \mathrm{~d} \zeta_{k}=0 \quad i=1,2,3 \quad$ and $\quad \int_{-1}^{+1} A_{i} A_{j} \mathrm{~d} \zeta_{k}=0 i \neq j$

At this stage, $3 \times \mathrm{NC}+3$ generalized displacements are included in Eqs. (5) and (8).

It should be noted that it is not necessary to introduce transverse shear correction factors.

The following part is dedicated to the obtention of relations between kinematic unknowns from:

- lateral boundary conditions,

- interlaminar continuity conditions (displacement, transverse shear stress).

It should be noted that the physical meaning is kept.

\subsubsection{Continuity conditions and free conditions for the refined sinus model}

From the displacement field Eq. (5), some continuity conditions on displacements and interlaminar stress must be imposed. For an interface layer $k \epsilon\{2, \ldots, N C\}$ (see Fig. 2), we have:

- displacement continuity conditions as in [46] i.e.:

$\bar{u}_{\mathrm{loc}}^{(k)}\left(x_{1}, z_{k}, t\right)=\bar{u}_{\mathrm{loc}}^{(k-1)}\left(x_{1}, z_{k}, t\right) \quad k=2, \ldots, \mathrm{NC}$

$\hat{u}_{\text {loc }}^{(k)}\left(x_{1}, z_{k}, t\right)=\hat{u}_{\text {loc }}^{(k-1)}\left(x_{1}, z_{k}, t\right) \quad k=2, \ldots, \mathrm{NC}$

- transverse shear stress continuity between two adjacent layers:

$\sigma_{13}^{(k)}\left(x_{1}, z_{k}^{+}\right)=\sigma_{13}^{(k-1)}\left(x_{1}, z_{k}^{-}\right) \quad k=2, \ldots, \mathrm{NC}$

So, $3 * \mathrm{NC}-3$ conditions are imposed, which allow to reduce the number of unknowns to 6 generalized displacements.

Free conditions of the transverse shear stress on the upper and lower surfaces must also be verified. So, we have:

$\sigma_{13}^{(1)}\left(x_{1}, z=-\frac{h}{2}\right)=0 \quad$ and $\quad \sigma_{13}^{(\mathrm{NC})}\left(x_{1}, z=\frac{h}{2}\right)=0$

Finally, the number of generalized displacements is reduced to 4, which is independent from the number of layers.

\subsubsection{Relation between the generalized displacements}

Using the displacement notation introduced in Eq. (8), the conditions Eqs. (10)-(13) can be written under the following form:

$[A]\{v\}=\{b\} u_{31}^{1}\left(x_{1}, t\right)+\{c\}\left(\omega_{3}\left(x_{1}, t\right)+w\left(x_{1}, t\right)^{\prime}\right)$

where $[A]$ is a $(3 * \mathrm{NC}-1) \times(3 * \mathrm{NC}-1)$ matrix.

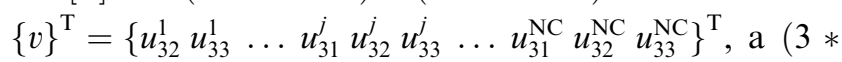
$\mathrm{NC}-1)$ vector, and $\{b\},\{c\}$ two $(3 * \mathrm{NC}-1)$ vectors.

From the resolution of this linear system, relations between $u_{31}^{j}(j \neq 1), u_{32}^{j}, u_{33}^{j}, j=1, \ldots, \mathrm{NC}$ and $u_{31}^{1}$ can be deduced. This relation can be written under the following form:

$$
\left\{\begin{array}{l}
u_{31}^{j}\left(x_{1}, t\right)=\beta_{1}^{j}\left(\omega_{3}\left(x_{1}, t\right)+w\left(x_{1}, t\right)^{\prime}\right)+\delta_{1}^{j} u_{31}^{1}\left(x_{1}, t\right), \\
j=1, \ldots, \mathrm{NC} \\
u_{32}^{j}\left(x_{1}, t\right)=\beta_{2}^{j}\left(\omega_{3}\left(x_{1}, t\right)+w\left(x_{1}, t\right)^{\prime}\right)+\delta_{2}^{j} u_{31}^{1}\left(x_{1}, t\right), \\
j=1, \ldots, \mathrm{NC} \\
u_{33}^{j}\left(x_{1}, t\right)=\beta_{3}^{j}\left(\omega_{3}\left(x_{1}, t\right)+w\left(x_{1}, t\right)^{\prime}\right)+\delta_{3}^{j} u_{31}^{1}\left(x_{1}, t\right), \\
j=1, \ldots, \mathrm{NC} \\
\quad \text { with }\left(\delta_{1}^{1}=1, \beta_{1}^{1}=0\right)
\end{array}\right.
$$

where $\delta_{1}^{j}, \delta_{2}^{j}, \delta_{3}^{j}$, and $\beta_{1}^{j}, \beta_{2}^{j}, \beta_{3}^{j}$ are the coefficients deduced from Eq. (14).

Finally, the four unknowns become $u, w, \omega_{3}$, and $u_{31}^{1}$.

\subsubsection{Linear part of strain}

Matrix notations can be easily defined using a generalized displacement vector as:

$[u]^{\mathrm{T}}=\left[F_{u}(z)\right]\left[\mathcal{E}_{u}\right]$

with $\left[\mathcal{E}_{u}\right]^{\mathrm{T}}=\left[\begin{array}{llllllll}u & \vdots & w & w, 1 & \vdots & \omega_{3} & \vdots & u_{31}^{1}\end{array}\right]$

and $\left[F_{u}(z)\right]$ is depending on the normal coordinate $z$. Its expression is given below:

$\left[F_{u}(z)\right]=\left[\begin{array}{ccccc}1 & 0 & F_{u 13}(z) & F_{u 14}(z) & F_{u 15}(z) \\ 0 & 1 & 0 & 0 & 0\end{array}\right]$

where

$F_{u 13}(z)=-z+f(z)+S_{\beta}(z)$

$F_{u 14}(z)=f(z)+S_{\beta}(z)$

$F_{u 15}(z)=S_{\delta}(z)$

and

$$
\begin{aligned}
S_{\beta}(z)= & \sum_{k=1}^{\mathrm{NC}}\left(\zeta_{k} \beta_{1}^{k}+\left(-\frac{1}{2}+\frac{3 \zeta_{k}^{2}}{2}\right) \beta_{2}^{k}+\left(-\frac{3 \zeta_{k}}{2}+\frac{5 \zeta_{k}^{3}}{2}\right) \beta_{3}^{k}\right) \\
& \times \Delta H(k, k+1) \\
S_{\delta}(z)= & \sum_{k=1}^{\mathrm{NC}}\left(\zeta_{k} \delta_{1}^{k}+\left(-\frac{1}{2}+\frac{3 \zeta_{k}^{2}}{2}\right) \delta_{2}^{k}+\left(-\frac{3 \zeta_{k}}{2}+\frac{5 \zeta_{k}^{3}}{2}\right) \delta_{3}^{k}\right) \\
& \times \Delta H(k, k+1)
\end{aligned}
$$

with $\Delta H(k, k+1)=H\left(z-z_{k}\right)-H\left(z-z_{k+1}\right)$. 
The linear part of the strains for the symmetric laminated beam element is:

$\varepsilon_{\mathrm{L} 11}=u_{, 1}-z w_{, 11}+\left(f(z)+S_{\beta}(z)\right)\left(w_{, 11}+\omega_{3,1}\right)+S_{\delta}(z) u_{31,1}^{1}$

$\gamma_{\mathrm{L} 13}=\left(f(z)_{, 3}+S_{\beta}(z)_{, 3}\right)\left(w_{, 1}+\omega_{3}\right)+S_{\delta}(z)_{, 3} u_{31}^{1}$

These expression can be described using a matrix notation:

$\left[\varepsilon_{\mathrm{L}}\right]=\left[F_{s}(z)\right]\left[\mathcal{E}_{s}\right]$ with

$\left[\mathcal{E}_{s}\right]^{\mathrm{T}}=\left[\begin{array}{llllllllll}u_{, 1} & \vdots & w_{, 1} & w_{, 11} & \vdots & \omega_{3} & \omega_{3,1} & \vdots & u_{31}^{1} & u_{31,1}^{1}\end{array}\right]$

and $\left[F_{s}(z)\right]$ is depending on the normal coordinate $z$. Its expression is given below: $\cup L_{e}^{h}(0)$ where (0) indicates the initial (fixed) configuration used.

The discrete boundary value problem is therefore formulated by the following Total Lagrangian functional available for non-linear analysis:

$$
\begin{aligned}
J\left(\vec{u}, \vec{u}^{*}\right)_{\cup L_{e}^{h}(0)}= & a\left(\vec{u}, \vec{u}^{*}\right)_{\cup L_{e}^{h}(0)}-f\left(\vec{u}^{*}\right)_{\cup U_{e}^{h}(0)} \\
& -F\left(\vec{u}^{*}\right)_{\partial \mathcal{B}_{F}(0)}=0, \quad \forall \vec{u}^{*}
\end{aligned}
$$

Absence of followed forces is considered here. Thus, the main feature of the non-linear formulation is incorporated into the virtual internal power $a\left(\vec{u}, \vec{u}^{*}\right)_{\cup L_{e}^{h}(0)}$ i.e.

$$
a\left(\vec{u}^{h}, \vec{u}^{* h}\right)_{L_{e}^{h}(0)}=\int_{L_{e}^{h}(0)} \int_{-h / 2}^{h / 2}\left[\varepsilon_{e}^{* h}\right]^{\mathrm{T}}\left[\bar{C}^{(k)}\right]\left[\varepsilon_{e}^{h}\right] \mathrm{d} z \mathrm{~d} L_{e}(0)
$$

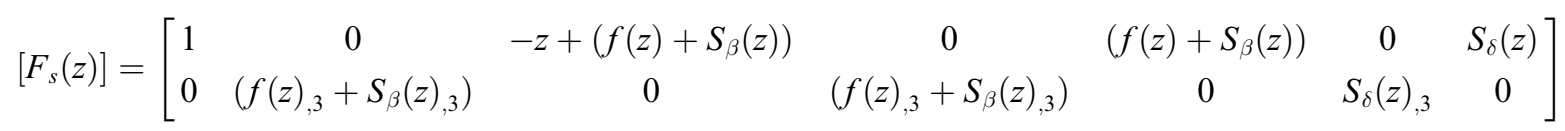

\subsubsection{Matrix expression for the weak form: linear part}

From the weak form of the boundary value problem Eq. (3), and using Eqs. (19) and (20), an integration throughout the cross-section is performed analytically in order to obtain an unidimensional formulation. Therefore, for a linear analysis, the first term of Eq. (4) can be written under the following form:

$$
\begin{gathered}
\int_{\mathcal{B}}\left[\varepsilon_{\mathrm{L}}\left(\vec{u}^{*}\right)\right]^{\mathrm{T}}\left[\sigma_{\mathrm{L}}(\vec{u})\right] \mathrm{d} \mathcal{B}=\int_{0}^{L}\left[\mathcal{E}_{s}^{*}\right]^{\mathrm{T}}[A]\left[\mathcal{E}_{s}\right] \mathrm{d} x_{1} \\
\text { with }[A]=\int_{\Omega}\left[F_{s}(z)\right]^{\mathrm{T}}[\bar{C}]\left[F_{s}(z)\right] \mathrm{d} \Omega
\end{gathered}
$$

where $[\bar{C}]$ is the constitutive unidimensional law given in Section 2.1.1, and $\Omega$ represents the cross-section $\left[-\frac{h}{2} \leqslant z \leqslant \frac{h}{2}\right] \times\left[-\frac{b}{2} \leqslant x_{2} \leqslant \frac{b}{2}\right]$.

In Eq. (21), matrix $[A]$ is the integration throughout the cross-section of the beam material characteristics. The interest of the Legendre polynomials choice can be emphasized in the calculation of the matrix $[A]$ owing to their properties of orthogonality (cf. Eq. (9)).

\section{The 1D three-node finite element for non-linear analyses}

This section is dedicated to the finite element approximation of the generalized displacement and the resolution of the non-linear mechanical problem, see matrices $\left[\mathcal{E}_{s}\right],\left[\mathcal{E}_{s}^{*}\right],\left[\mathcal{E}_{u}\right]$, and $\left[\mathcal{E}_{u}^{*}\right]$ (Eqs. (19) and (16)). It is briefly described, and the reader can obtain a detailed description in $[40,2]$.

\subsection{Non-linear finite element formulation}

The multilayered structure is considered in a Total Lagrangian configuration, so that its mesh is denoted

\subsection{The geometric approximation}

Given the displacement field constructed above for sandwich and laminated beams, a corresponding finite element is developed in order to analyze the behaviour of laminated beam structures under combined loads. Let us consider the eth element $L_{e}^{h}$ of the mesh $\cup L_{e}^{h}$. This element has three nodes, denoted by $\left(g_{j}\right)_{j=1,2,3}$, see Fig. 3 . The coordinate $x_{1}$ on the central line of the beam is approximated as follows:

$x_{1}(\xi)=\sum_{j=1}^{3} N q_{j}(\xi) x_{1}^{e}\left(g_{j}\right)$

where $N q_{j}(\xi)$ are Lagrange quadratic interpolation functions and $x_{1}^{e}\left(g_{j}\right)$ is the cartesian coordinate (measured along the $x_{1}$ axis) of the node $g_{j}$ of the element $L_{e}^{h}$. $\xi$ is an isoparametric or reduced coordinate and its variation domain is $[-1,1]$.

\subsection{Interpolation for the bending-traction beam element}

The finite element approximations of the assumed displacement field components are hereafter symbolically written as $u_{i}^{h}\left(x_{1}, x_{2}, z\right)$ where the superscript $h$ refers to the mesh $\cup L_{e}^{h}$.

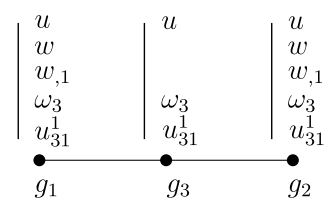

Fig. 3. Description of the laminated beam finite element dof. 
From the kinematics (see Eq. (5)), the transverse displacement $w^{h}$ must be $C^{1}$-continuous; whereas the rotation $\omega_{3}^{h}$, the extension displacement $u^{h}$ and $u_{31}^{1 h}$ can be only $C^{0}$ continuous. Therefore, the generalized displacement $w^{h}$ is interpolated by the Hermite cubic functions $N h_{j}(\xi)$.

According to the transverse shear locking phenomena, the other shear bending generalized displacements, rotation $\omega_{3}^{h}$, are interpolated by Lagrange quadratic functions denoted $N q_{j}(\xi)$. This choice allows the same order of interpolation for both $w_{11}^{h}$ and $\omega_{3}^{h}$ in the corresponding transverse shear strain components due to bending, and enables to avoid transverse shear locking using the field compatibility approach, see [48].

Finally, traction $u^{h}$ and $u_{31}^{1 h}$ are interpolated by Lagrange quadratic functions.

\subsection{Expression of strains}

All the quantities in Eq. (23) refer to the initial (fixed) configuration. Virtual strain rates and strains can be split into their linear (index L) and non-linear (index NL) parts as follows:

$$
\begin{aligned}
& {\left[\varepsilon_{e}^{* h}\right]=\left[\varepsilon_{\mathrm{L}_{e}}^{* h}\right]+\left[\varepsilon_{\mathrm{NL}_{e}}^{* h}\right]} \\
& {\left[\varepsilon_{e}^{h}\right]=\left[\varepsilon_{\mathrm{L}_{e}}^{h}\right]+\left[\varepsilon_{\mathrm{NL}_{e}}^{h}\right]}
\end{aligned}
$$

The geometrically non-linear formulation now considered is based on Von-Karmann assumptions where deflexion is moderately large, while rotations and strains are small. Non-linear parts in (25) are then given by

$$
\begin{aligned}
& {\left[\epsilon_{\mathrm{NL}_{e}}^{* h}\right]^{\mathrm{T}}=\left[\begin{array}{ll}
u_{3}^{h},{ }_{1} u_{3}^{* h}, 1 & 0
\end{array}\right]} \\
& {\left[\epsilon_{\mathrm{NL}_{e}}^{h}\right]^{\mathrm{T}}=\left[\begin{array}{ll}
\frac{1}{2} u_{3}^{h}, 1^{2} & 0
\end{array}\right]}
\end{aligned}
$$

The linear part in Eq. (25) is detailed in Section 2.2.3.

\subsection{Consistent linearization procedure}

From these latest equations, it is evident that expression (23) is non-linear with respect to displacements, and a Newton algorithm has to be used to find a numerical solution of Eq. (22). For a Newton-type method, knowledge of the tangent stiffness is required and can be derived using standard linearization procedures. Applying it to Eq. (22), we obtain

$J\left(\vec{u}^{h}, \vec{u}^{* h}\right)_{\cup L_{e}(0)}=J\left(\overrightarrow{\vec{u}}^{h}, \vec{u}^{* h}\right)_{\cup L_{e}(0)}+D_{\vec{u}} J\left(\overrightarrow{\vec{u}}^{h}, \vec{u}^{* h}\right) \cdot \Delta \vec{u}^{h}$

with $\vec{u}^{h}=\overrightarrow{\vec{u}}^{h}+\Delta \vec{u}^{h}$, where $\overrightarrow{\vec{u}}^{h}$ refers to a known state.

According to Eq. (27), the linearized form of the functional (22) is deduced and we now have to find the solution of the following equation:

$$
\begin{aligned}
D_{\vec{u}} a\left(\overrightarrow{\vec{u}}^{h}, \vec{u}^{* h}\right)_{\cup L_{e}(0)} \cdot \Delta \vec{u}^{h}= & -a\left(\overrightarrow{\vec{u}}^{h}, \vec{u}^{* h}\right)_{\cup L_{e}(0)}+f\left(\vec{u}^{* h}\right)_{\cup L_{e}(0)} \\
& +F\left(\vec{u}^{* h}\right)_{\cup \partial \mathcal{B}_{F e}(0)}, \quad \forall \vec{u}^{* h}
\end{aligned}
$$

The left member of Eq. (28) has to be computed and gives the tangent operator, while other quantities in the right member are known vectors as they depend only on the known state $\overrightarrow{\vec{u}}^{h}$.

\subsection{Tangent stiffness matrix}

The tangent stiffness matrix is now derived from the left member of Eq. (28). For an arbitrary finite element $L_{e}(0)$ of the mesh $\cup L_{e}(0)$, the tangent operator is found as

$$
\begin{aligned}
D_{\vec{u}} a\left(\overrightarrow{\vec{u}}^{h}, \vec{u}^{* h}\right)_{L_{e}(0)} \cdot \Delta \vec{u}^{h}= & \int_{L_{e}(0)}\left[\mathcal{E}_{s e}^{* h}\right]^{\mathrm{T}}\left[A_{e}\right]\left[\Delta \mathcal{E}_{s e}^{h}\right] \mathrm{d} L_{e}(0) \\
& +\int_{L_{e}(0)}\left[\mathcal{E}_{s e}^{* h}\right]^{\mathrm{T}}\left[A_{e}\left(\overrightarrow{\bar{u}}^{h}\right)\right]\left[\Delta \mathcal{E}_{s e}^{h}\right] \mathrm{d} L_{e}(0) \\
& +\int_{L_{e}(0)}\left[\mathcal{E}_{s e}^{* h}\right]^{\mathrm{T}}\left[A_{e}\left(\bar{\sigma}^{h}\right)\right]\left[\Delta \mathcal{E}_{s e}^{h}\right] \mathrm{d} L_{e}(0)
\end{aligned}
$$

In Eq. (29), the matrix $\left[A_{e}\right]$ has been given in Section 2.2.4 (see Eq. (21)), as well as vectors $\left[\mathcal{E}_{s e}^{h}\right]$ and $\left[\Delta \mathcal{E}_{s e}^{h}\right]=\Delta\left[\mathcal{E}_{s e}^{h}\right]$ from Eq. (19). The matrix $\left[A_{e}\left(\overrightarrow{\vec{u}}^{h}\right)\right]$ depends on material properties and on both linear and quadratically known state $\overrightarrow{\vec{u}}^{h}$. Finally, the matrix $\left[A_{e}\left(\bar{\sigma}^{h}\right)\right]$ is linked to the in-plane stresses. Expressions for these last two matrices are given in Appendices A.1 and A.2.

Following the procedure given in Section 2 to derive the linear stiffness matrix $\left[K_{e}\right]$, it is easy to compute the tangent stiffness matrix, denoted $\left[K_{T e}\right]$, so that

$D_{\vec{u}} a\left(\overrightarrow{\vec{u}}^{h}, \vec{u}^{* h}\right)_{L_{e}(0)} \cdot \Delta \vec{u}^{h}=\left[q_{e}^{*}\right]^{\mathrm{T}}\left[K_{\mathrm{T} e}\right]\left[\Delta q_{e}\right]$

where

$\left[K_{\mathrm{T} e}\right]=\left[K_{e}\right]+\left[K_{e}\left(\overrightarrow{\vec{u}}^{h}\right)\right]+\left[K_{e}\left(\bar{\sigma}^{h}\right)\right]$

In Eq. (31), to compute either matrix $\left[K_{e}\right]$ or $\left[K_{e}\left(\overrightarrow{\vec{u}}^{h}\right)\right]$ or $\left[K_{e}\left(\bar{\sigma}^{h}\right)\right]$, we use Eq. (32) detailed in the next section, respectively based either on $\left[A_{e}\right]$ or $\left[A_{e}\left(\overrightarrow{\vec{u}}^{h}\right)\right]$ or $\left[A_{e}\left(\bar{\sigma}^{h}\right)\right]$.

\subsection{Elementary matrices}

In the Section 2.2, all the finite element mechanical approximations were defined, and elementary rigidity $\left[K_{e}\right]$ matrix can be deduced from Eq. (21). It has the following expression:

$\left[K_{e}\right]=\int_{L_{e}}\left[B_{e}\right]^{\mathrm{T}}\left[A_{e}\right]\left[B_{e}\right] \mathrm{d} L_{e}$

where $\left[B_{e}\right]$ is deduced expressing the generalized displacement vectors, see Eq. (19), from the elementary vector of degrees of freedom (dof) denoted $\left[q_{e}\right]$ by:

$\left[\mathcal{E}_{s e}^{h}\right]=\left[B_{e}\right]\left[q_{e}\right]$

The matrix $\left[B_{e}\right]$ contains only the interpolation functions, their derivatives and the jacobian components.

The same technique can be used defining the elementary matrices $\left[K_{e}\left(\overrightarrow{\vec{u}}^{h}\right)\right]$ and $\left[K_{e}\left(\bar{\sigma}^{h}\right)\right]$.

\section{Numerical results and discussions}

In this section, several non-linear tests are presented evaluating the efficiency of our finite element. It is to be 
noted that this finite element has showed very good properties in the context of linear analysis, i.e. static and vibration tests (see [2]). In particular, there is no need for transverse shear correction factors. Convergence velocity is high, and accurate results have been obtained for different benchmarks. So, we want to extend these characteristics to non-linear analysis.

\subsection{Critical buckling}

The critical buckling load value is found by solving the following eigenvalue problem:

$([K]-\lambda[K(\bar{\sigma})])[q]=[0]$

In the following sections, buckling predictions are validated against results obtained by other available higher-order shear-deformation theory or $2 \mathrm{D}$ analysis.

\subsubsection{Convergence study}

Before proceeding to the detailed analysis, numerical computations are carried out for convergence properties.

As in [13], an isotropic beam is considered to study the shear-deformation effect and the refinement of the mesh on the buckling load. This test is detailed below:

Geometry: the beam studied has a length of $L=0.0254 \mathrm{~m}$, and a thickness $h=0.00254 \mathrm{~m}(S=$ 10), $b=0.003048 \mathrm{~m}$.

Boundary conditions: simply supported beam.

Material properties: isotropic beam with $E=1.379 \times 10^{9} \mathrm{~Pa}, G=0.6895 \times 10^{9} \mathrm{~Pa}, \quad$ or $\quad G=$ $0.6895 \times 10^{8} \mathrm{~Pa}$.

Mesh: $N=2,4,8,16$.

Table 2

Critical buckling load parameter obtained by various beam theories for homogeneous beams $(\mathrm{kN})-S=10$

\begin{tabular}{lrrll}
\hline Models & $N$ & dof nb & $\begin{array}{l}G=0.6895 \times \\
10^{9} \mathrm{~Pa}\end{array}$ & $G=0.6895 \times 10^{8} \mathrm{~Pa}$ \\
\hline SinRef-c & 2 & 16 & 86.7432 & 73.8207 \\
& 4 & 32 & 86.1514 & 73.3914 \\
& 8 & 64 & 86.111 & 73.362 \\
& 16 & 128 & 86.1083 & 73.360 \\
HSDT [49] & 2 & & 86.0859 & 73.0340 \\
& 4 & & 85.4426 & 72.9421 \\
& 20 & & 85.4321 & 72.9407 \\
Analytical [49] & & & 86.1043 & 73.3295 \\
\hline
\end{tabular}

Results: critical buckling load; comparison with analytical results [49] and higher-order shear-deformation theory [13] (third-order expansion in the thickness) for a finite element model.

The results are compared with the buckling loads obtained from the mechanics of materials solution including shear effects, such that: $P_{\mathrm{cr}}=\frac{P_{e}}{\left(1+P_{e} k /(G b h)\right)}$ with $P_{e}=\pi^{2} E I / L^{2}$ and $k=5 / 6$. The results of HSDT model are also given from [13] in Table 2. In this approach, a four-node straight-beam element with 56 dofs per node is used.

The convergence of the SinRef-c model is very high. Moreover, the efficiency of this model is better than the HSDT model.

The second example is issued from $[14,15]$. It deals with a symmetric laminated composite with the following characteristics:

Geometry: the beam studied has a length of $L=6.35 \mathrm{~m}$, and a thickness $h=0.2794 \mathrm{~m}$ (thin $S \approx 22.7$ ). The layup is $\left(90^{\circ} / 0^{\circ} / 90^{\circ}\right)$, with thickness $(0.25 h / 0.5 h / 0.25 h)$.

Boundary conditions: simply supported beam.

Material properties: the material used is boron epoxy which has the following mechanical properties:

$$
\begin{aligned}
& E_{11}=241.5 \mathrm{GPa}, \quad E_{22}=E_{33}=18.89 \mathrm{GPa}, \\
& G_{12}=G_{13}=5.18 \mathrm{GPa} \quad G_{23}=3.45 \mathrm{GPa}, \\
& \nu_{12}=\nu_{13}=0.24, \quad \nu_{23}=0.25 \\
& \rho=2015 \mathrm{~kg} / \mathrm{m}^{3} . \\
& \text { Mesh: } N=1,2,4,8,12 . \\
& \text { Results: critical loads for buckling. }
\end{aligned}
$$

Table 3 gives the convergence of the SinRef-c model for the critical buckling load. The results obtained are in good agreement with the reference values with few elements. In particular, a $N=2$ mesh gives excellent results for the three modes. Based on progressive mesh refinement, a $N=8$ mesh is adequate to model the laminated beam for a buckling analysis.

\subsubsection{Buckling of laminated composite beam}

4.1.2.1. Influence of length to thickness ratio and boundary conditions [1]. Analytical solutions of refined beam theories (third-order beam theory) are compared with SinRef-c model. The buckling behaviour of cross-ply rectangular beams with arbitrary boundary conditions is studied. The considered test has the following characteristics:

Table 3

Critical loads for the buckling of a simply supported beam (thin beam)

\begin{tabular}{lccccccccccc}
\hline Mode & $N=1$ & err $(\%)$ & $N=2$ & err $(\%)$ & $N=4$ & err & $N=8$ & err $(\%)$ & $N=12$ & err $(\%)$ & Abaqus $[14]$ \\
\hline 1 & $2.466 \mathrm{e} 7$ & 21 & $2.040 \mathrm{e} 7$ & 0.1 & $2.040 \mathrm{e} 7$ & 0.1 & $2.039 \mathrm{e} 7$ & 0.04 & $2.039 \mathrm{e} 7$ & 0.04 & $2.0381 \mathrm{e} 7$ \\
2 & $11.084 \mathrm{e} 7$ & 45 & $7.674 \mathrm{e} 7$ & 0.4 & $7.674 \mathrm{e} 7$ & 0.4 & $7.626 \mathrm{e} 7$ & 0.2 & $7.623 \mathrm{e} 7$ & 0.2 & $7.6407 \mathrm{e} 7$ \\
3 & - & - & $15.896 \mathrm{e} 7$ & 1.3 & $15.896 \mathrm{e} 7$ & 1.3 & $15.506 \mathrm{e} 7$ & 1.1 & $15.47 \mathrm{e} 7$ & 1.3 & $15.684 \mathrm{e} 7$ \\
\hline
\end{tabular}


Geometry: the beam studied has a length of $L$, and a thickness $h$ (thin $S=5, S=10$ ). It possesses three layers at $\left(0^{\circ} / 90^{\circ} / 0^{\circ}\right)$, with the same thickness.

Boundary conditions: hinged-hinged, clamped-hinged, clamped-clamped, clamped-free

clamped: $\quad u_{i}=w_{i}=w_{i, x}=\omega_{3 i}=u_{31 i}^{1}=0 \quad$ for $\quad$ the node $i$

hinged: $w_{i}=0$

Material properties: $\frac{E_{1}}{E_{2}}=40 ; G_{12}=G_{13}=0.6 E_{2} ; G_{23}=$ $0.5 E_{2}, \nu_{12}=0.25$.

Mesh: $N=8$.

Results: critical buckling loads are non-dimensionalized as: $\bar{N}=\frac{N L^{2}}{E_{2} b h^{3}}$. They are compared to the third-order theory of Reddy (TOBT).

The results for different length to thickness ratios and boundary conditions are given in Table 4 . As one can observe, the critical loads for the SinRef-c model are always lower than these of the TOBT. Nevertheless, these values are very close.

\subsubsection{Influence of stacking sequences. Different cross-ply} laminates are considered as follows:

Geometry: the beam studied has a length of $L$, and a thickness $h(S=10)$. stacking sequencies: $\left(0^{\circ}\right),\left(0^{\circ} / 90^{\circ}\right)$, $\left(0^{\circ} / 90^{\circ} / 0^{\circ}\right),\left(0^{\circ} / 90^{\circ} / 0^{\circ} / 90^{\circ}\right)$, layers with the same thickness.

Boundary conditions: simply supported beam.

Material properties: $\quad E_{1}=181 \mathrm{GPa}, E_{2}=E_{3}=10.3$ $\mathrm{GPa}, G_{12}=G_{13}=7.17 \mathrm{GPa}, G_{23}=6.21 \mathrm{GPa}, \nu_{12}=$ $0.28, \nu_{13}=0.02, \nu_{23}=0.40$.

Mesh: $N=8$.

Results: critical buckling loads are non-dimensionalized as: $\lambda=p_{\text {cr }} /\left[h^{2} / L^{2} E_{2} h /\left(1-\nu_{12} \nu_{21}\right)\right]$ issued from [50] (beam finite element model using a higher-order shear deformation theory).

Table 5 shows a good agreement between the two theories regardless of the stacking sequence.

4.1.2.3. Influence of boundary conditions. A set of boundary conditions is considered as in [18]. The results are compared with the ones available in the literature for different stacking sequences and length-to-thickness ratios. Only critical loads of higher-order shear deformation theory are presented for comparison, see [18] for more details. It
Table 5

Critical buckling load parameter obtained by various beam theories for homogeneous and cross-ply beams $-S=10$

\begin{tabular}{lllll}
\hline Models & $\left(0^{\circ}\right)$ & $\left(0^{\circ} / 90^{\circ}\right)$ & $\left(0^{\circ} / 90^{\circ} / 0^{\circ}\right)$ & $\left(0^{\circ} / 90^{\circ} / 0^{\circ} / 90^{\circ}\right)$ \\
\hline SinRef-c & 11.567 & 2.8937 & 11.0945 & 5.7703 \\
HSDT [50] & 11.5255 & 2.9172 & 11.0573 & 5.7511 \\
\hline
\end{tabular}

should be noted that this theory does not ensure the continuity of the transverse shear stress on the interfaces between the layers for the unsymmetric beam. This limitation does not exist in our approach. Nevertheless, these theories are compared here.

The tests are characterized by

Geometry: the beam studied has a length of $L$, and a thickness $h(S=10)$. stacking sequencies: $\left(0^{\circ} / 90^{\circ}\right),\left(0^{\circ} \%\right.$ $\left.90^{\circ} / 0^{\circ}\right)$, layers with the same thickness.

Boundary conditions: simply supported beam (SS), clamped-free (CF), clamped-simply supported (CS).

Material properties: two material are considered:

mat I: $\frac{E_{1}}{E_{2}}=$ open; $G_{12}=G_{13}=0.6 E_{2} ; G_{23}=0.5 E_{2} ; \nu_{12}=$ 0.25

mat II: $\quad \frac{E_{1}}{E_{2}}=$ open; $G_{12}=G_{13}=0.5 E_{2} ; G_{23}=$ $0.2 E_{2} ; \nu_{12}=0.25$.

Mesh: $N=8$

Results: critical buckling loads are non-dimensionalized as: $\lambda=N_{\mathrm{cr}} L^{2} / b E_{2} h^{3}$ issued from [18]. HSDBT and

Table 6

Dimensionless critical buckling loads $-\left(0^{\circ} / 90^{\circ} / 0^{\circ}\right)\left(E_{1} / E_{2}=40\right)$

\begin{tabular}{|c|c|c|c|c|c|c|c|}
\hline \multirow[t]{2}{*}{ Models } & \multirow[t]{2}{*}{$S$} & \multicolumn{2}{|l|}{ CS } & \multicolumn{2}{|l|}{ SS } & \multicolumn{2}{|l|}{$\mathrm{CF}$} \\
\hline & & mat I & mat II & mat I & mat II & mat I & mat II \\
\hline \multirow{2}{*}{ SinRef-c } & 5 & 9.674 & 6.192 & 8.593 & 5.473 & 4.704 & 3.440 \\
\hline & 20 & 46.856 & 37.288 & 27.076 & 23.763 & 7.610 & 7.319 \\
\hline \multirow[t]{2}{*}{ HSDBT [18] } & 5 & 9.317 & 8.951 & 8.162 & 7.465 & 4.554 & 4.226 \\
\hline & 20 & 45.813 & 43.390 & 26.752 & 25.944 & 7.584 & 7.516 \\
\hline
\end{tabular}

Table 7

Dimensionless critical buckling loads $-\left(0^{\circ} / 90^{\circ} / 0^{\circ}\right)\left(E_{1} / E_{2}=10\right)$

\begin{tabular}{|c|c|c|c|c|c|c|c|}
\hline \multirow[t]{2}{*}{ Models } & \multirow[t]{2}{*}{$S$} & \multicolumn{2}{|l|}{ CS } & \multicolumn{2}{|l|}{ SS } & \multicolumn{2}{|l|}{$\mathrm{CF}$} \\
\hline & & mat I & mat II & mat I & mat II & mat I & mat II \\
\hline \multirow[t]{2}{*}{ SinRef-c } & 5 & 6.468 & 4.320 & 4.722 & 3.447 & 1.702 & 1.492 \\
\hline & 20 & 14.907 & 13.736 & 7.665 & 7.368 & 1.978 & 1.958 \\
\hline \multirow[t]{2}{*}{ HSDBT [18] } & 5 & 6.187 & 5.667 & 4.572 & 4.246 & 1.683 & 1.632 \\
\hline & 20 & 14.797 & 14.797 & 7.639 & 7.571 & 1.977 & 1.973 \\
\hline
\end{tabular}

Table 4

Effect of length to thickness ratio on the dimensionless critical buckling loads obtained by various beam theories $-\left(0^{\circ} / 90^{\circ} / 0^{\circ}\right)$

\begin{tabular}{cllccc}
\hline$S$ & Models & Clamped-free & Hinged-hinged & Clamped-hinged & Clamped-clamped \\
\hline 5 & SinRef-c & 4.704 & 8.593 & 9.674 & 11.289 \\
& TOBT [1] & 4.708 & 8.613 & 9.814 & 11.652 \\
10 & & & & & 25.810 \\
\\
& SinRef-c & 6.769 & 18.816 & 25.857 & 34.377 \\
\hline
\end{tabular}


Table 8

Dimensionless critical buckling loads $-\left(0^{\circ} / 90^{\circ}\right)\left(E_{1} / E_{2}=40\right)$

\begin{tabular}{|c|c|c|c|c|c|c|c|}
\hline \multirow[t]{2}{*}{ Models } & \multirow[t]{2}{*}{$S$} & \multicolumn{2}{|l|}{$\mathrm{CS}$} & \multicolumn{2}{|l|}{ SS } & \multicolumn{2}{|l|}{$\mathrm{CF}$} \\
\hline & & mat I & mat II & mat I & mat II & mat I & mat II \\
\hline \multirow[t]{2}{*}{ SinRef-c } & 5 & 4.960 & 4.250 & 3.439 & 3.107 & 1.181 & 1.139 \\
\hline & 20 & 10.249 & 10.030 & 5.232 & 5.179 & 1.344 & 1.340 \\
\hline \multirow[t]{2}{*}{$\operatorname{HSDBT}_{\mathrm{ds}}[18]$} & 5 & 5.976 & 4.780 & 3.903 & 3.372 & 1.236 & 1.175 \\
\hline & 20 & 10.521 & 10.216 & 5.296 & 5.224 & 1.349 & 1.344 \\
\hline
\end{tabular}

Table 9

Dimensionless critical buckling loads $-\left(0^{\circ} / 90^{\circ}\right)\left(E_{1} / E_{2}=10\right)$

\begin{tabular}{|c|c|c|c|c|c|c|c|}
\hline \multirow[t]{2}{*}{ Models } & \multirow[t]{2}{*}{$S$} & \multicolumn{2}{|l|}{$\mathrm{CS}$} & \multicolumn{2}{|l|}{ SS } & \multicolumn{2}{|l|}{$\mathrm{CF}$} \\
\hline & & mat I & mat II & mat I & mat II & mat I & mat II \\
\hline \multirow[t]{2}{*}{ SinRef-c } & 5 & 3.207 & 2.799 & 1.887 & 1.750 & 0.539 & 0.527 \\
\hline & 20 & 4.509 & 4.452 & 2.238 & 2.225 & 0.565 & 0.564 \\
\hline \multirow{2}{*}{$\mathrm{HSDBT}_{\mathrm{ds}}[18]$} & 5 & 3.303 & 2.845 & 1.919 & 1.765 & 0.542 & 0.528 \\
\hline & 20 & 4.521 & 4.458 & 2.241 & 2.226 & 0.565 & 0.564 \\
\hline
\end{tabular}

$\mathrm{HSDBT}_{\mathrm{ds}}$ stand for hyperbolic shear deformation beam theory and discontinuity interlaminar stresses respectively.

The critical buckling loads for symmetric and anti-symmetric composite beams are given in Tables 6-9 with respect to span-to-thickness ratio (thick $S=5$, moderately thick $S=20$ ), boundary condition, and material.

For the three layers case:

- the difference between the two theories can be more appreciated for the material II,

- the value of the critical load for the SinRef-c model is lower than the corresponding HSDBT value for the material I,

- it is the reverse for the material II.

For the two layers beam:

- it should be noted that the results issued from the SinRef-c model take lower values than the corresponding HSDBT case (discontinuous case) regardless of the material, the boudary condition, and the length-tothickness ratio,

- as in [18], the critical loads are close for CF boundary condition, especially for $E_{1} / E_{2}=10$ (Table 9).

\subsubsection{Buckling of sandwich beam}

As in [34], the particular case of a sandwich beam is considered as follows:

Geometry: the 3-layer sandwich beam has graphiteepoxy faces and a soft core with thickness $0.1 h / 0.8 h /$ $0.1 \mathrm{~h}$ and length to thickness ratio from $S=5$ to $S=100$.

Boundary conditions: simply supported beam.
Table 10

Critical strains $\bar{\varepsilon}_{\text {cr }}$ for sandwich beam

\begin{tabular}{clll}
\hline$S$ & SinRef-c & Error $(\%)$ & 2D [34] \\
\hline 5 & -0.4404 & 4 & -0.4220 \\
7.5 & -0.7746 & 3 & -0.747 \\
10 & -1.058 & 3 & -1.028 \\
20 & -1.638 & 1 & -1.620 \\
100 & -1.989 & 0.0 & -1.989 \\
\hline
\end{tabular}

Material properties: Face: $E_{11}=131.1 \mathrm{GPa}, E_{22}=E_{33}=$ $6.9 \mathrm{GPa}, G_{12}=3.588 \mathrm{GPa}, G_{13}=3.088 \mathrm{GPa}, G_{23}=$ $2.3322 \mathrm{GPa}, \nu_{12}=\nu_{13}=0.32, \nu_{23}=0.49, \rho_{\mathrm{f}}=1000 \mathrm{~kg} / \mathrm{m}^{3}$. Core: $\quad E_{11}=0.2208 \mathrm{MPa}, E_{22}=0.2001 \mathrm{MPa}, E_{33}=2760$ $\mathrm{MPa}, G_{12}=16.56 \mathrm{MPa}, G_{13}=545.1 \mathrm{MPa}, G_{23}=455.4 \mathrm{MPa}$, $\nu_{12}=0.99, \nu_{13}=0.00003, \nu_{23}=0.00003, \rho_{\mathrm{c}}=70 \mathrm{~kg} / \mathrm{m}^{3}$.

Results: critical strains $\bar{\varepsilon}_{\mathrm{cr}}=\varepsilon_{\mathrm{cr}} S^{2}$ with $\varepsilon_{\mathrm{cr}}=$ $-N_{\mathrm{cr}} /\left(\int_{z} C_{11} \mathrm{~d} z\right) b$.

In Table 10, the results of the present model are compared to exact solution of 2D elastic buckling formulation for different span-to-thickness ratios. It should be noted that the error remains low for very thick and thin beams.

\subsection{Post-buckling analyses}

In this part, three stacking sequences $\left(0^{\circ} / 90^{\circ}\right),\left(0^{\circ} / 90^{\circ} /\right.$ $\left.0^{\circ}\right)$, and $\left(0^{\circ} / 90^{\circ} / 0^{\circ} / 90^{\circ} / 0^{\circ}\right)$ are considered in post-buckling analyses. The tests have the following characteristics:

Geometry: the beam studied has a length of $L=6.35 \mathrm{~m}$, and a thickness $h=0.2794 \mathrm{~m}$ (thin $S \approx 22.7$ ). It possesses two layers $(0.5 \mathrm{~h} / 0.5 \mathrm{~h})$, three layers $(0.25 h / 0.5 h /$ $0.25 h$ ), and five layers (with equal thickness $h / 5$ ).

Boundary conditions: simply supported beam with a transverse perturbation load $F_{\text {per }}$.

Material properties: the material used is boron epoxy which has the following mechanical properties:

$E_{11}=241.5 \mathrm{GPa}, \quad E_{22}=E_{33}=18.89 \mathrm{GPa}$,

$G_{12}=G_{13}=5.18 \mathrm{GPa}, \quad G_{23}=3.45 \mathrm{GPa}$,

$\nu_{12}=\nu_{13}=0.24, \quad \nu_{23}=0.25$

$\rho=2015 \mathrm{~kg} / \mathrm{m}^{3}$.

Mesh: $N=12$.

Results: post-buckling, $F / w$.

The variation of $F$ with respect to transverse displacement $w$ is presented in Figs. 4-6. The results are compared with 2D finite element solution (ANSYS). It is seen from these figures that the present finite element performs quite well for all cases.

\subsection{Non-linear analyses}

In this section, the computation of the non-linear response, with respect to the Von Karman assumption, 


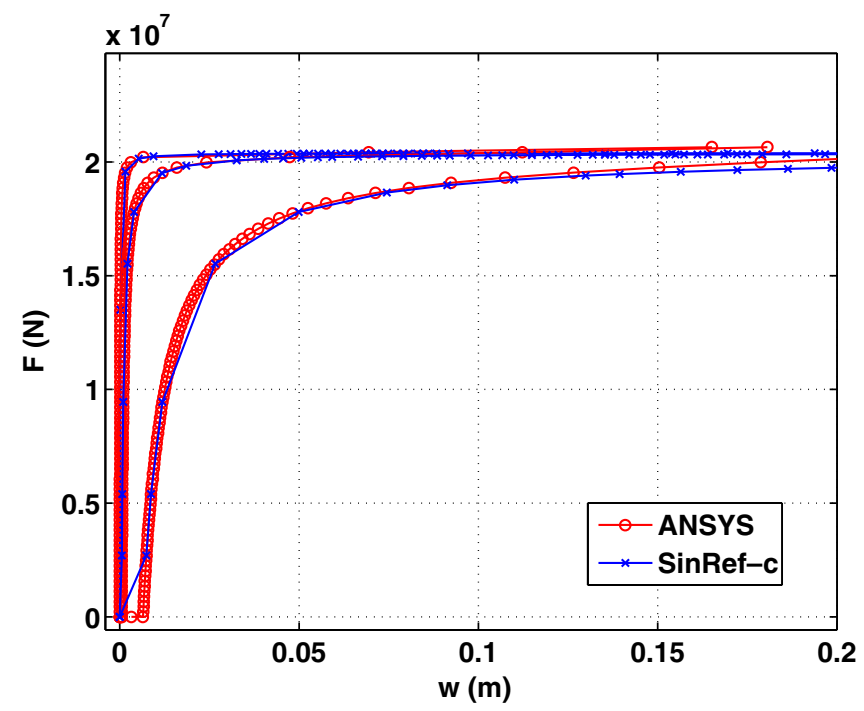

Fig. 4. $F / w$ with $F_{\text {per }}=1000 \mathrm{~N}, F_{\text {per }}=8000 \mathrm{~N}, F_{\text {per }}=100,000 \mathrm{~N}-$ three layers.

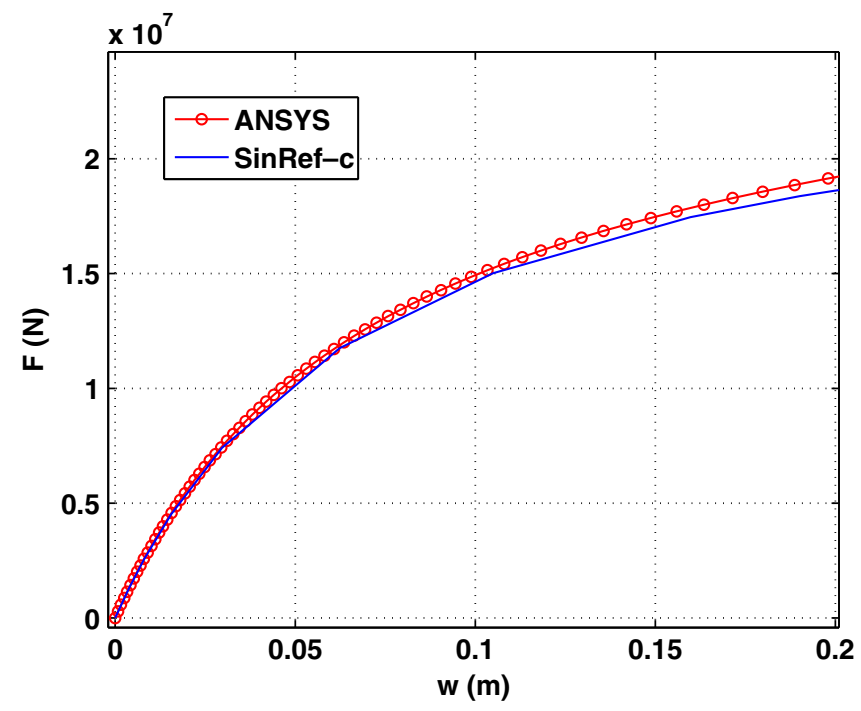

Fig. 5. $F / w$ with $F_{\text {per }}=1 \mathrm{e}-9 \mathrm{~N}-$ two layers.

for a beam subject to a transverse load is achieved by solving:

$\left[K_{\mathrm{T}}\right][\Delta q]=[\Delta F]-\left([K]+\left[K_{\mathrm{NL}}(\bar{q})\right]\right)[\bar{q}]$

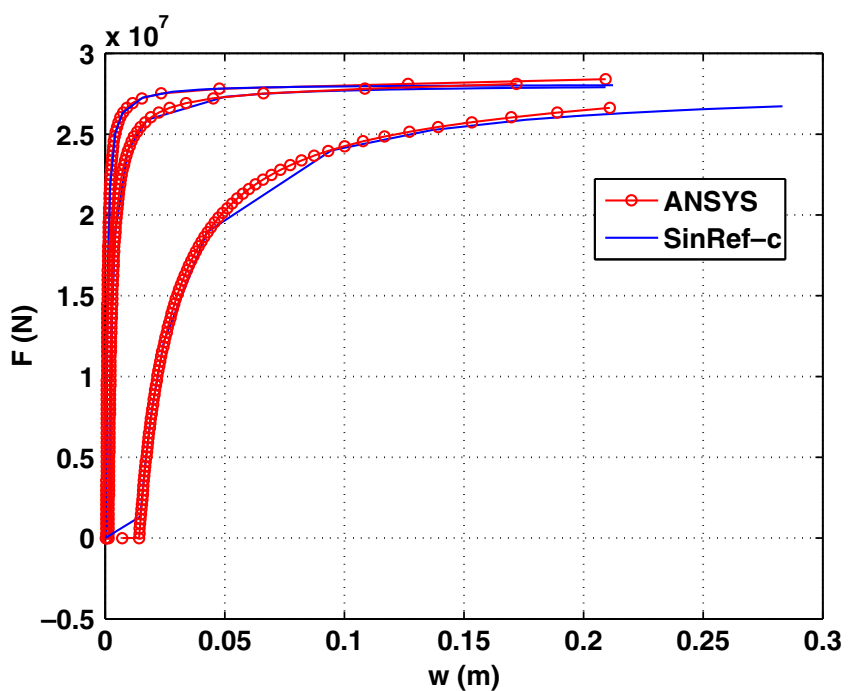

Fig. 6. $F / w$ with $F_{\text {per }}=10000 \mathrm{~N}, F_{\text {per }}=30000 \mathrm{~N}, F_{\text {per }}=300,000 \mathrm{~N}-$ five layers.

where $[\Delta F]$ is the incremental applied load matrix and $\left[K_{\mathrm{NL}}(\bar{q})\right]$ is the non linear rigidity matrix terms.

Two stacking sequences of laminated composite are considered for non-linear bending tests:

Geometry: the beam studied has a length of $L=6.35 \mathrm{~m}$, and a thickness $h=0.2794 \mathrm{~m}$ (thin $S \approx 22.7$ ). It possesses three layers at $\left(90^{\circ} / 0^{\circ} / 90^{\circ}\right)$, with thickness $(0.25 h / 0.5 h / 0.25 h)$ - two layers at $\left(90^{\circ} / 0^{\circ}\right)-(0.5 h / 0.5 h)$.

Boundary conditions: clamped-clamped - sinusoidal pressure $p\left(x_{1}\right)=F \sin \left(\pi x_{1} / L\right)$.

Material properties: same material as in Section 4.2.

Mesh: $N=8$.

Results: Non-linear bending test, transverse displacement $\bar{w}=w / h$ with respect to $F$.

The same study is carried out with the commercial code ANSYS [51]. A very refined mesh with 7980 dofs in a 2D analysis is considered as a reference.

Tables 11 and 12 present numerical values of force and transverse displacement for symmetric and anti-symmetric beams. These results show the excellent agreement with reference values. The maximal \% error is 2 . Figs. 7 and 8 show

Table 11

Non-linear bending analysis $-\left(90^{\circ} / 0^{\circ} / 90^{\circ}\right)-S=22.7$ - clamped-clamped

\begin{tabular}{llllllllll}
\hline$F\left({ }^{*} 1 \mathrm{e} 6 \mathrm{~N}\right)$ & 1 & 1.5 & 2 & 2.5 & 3.5 & 4.5 & 8 & 10 \\
\hline$w$ SinRef-c & -0.0441 & -0.0628 & -0.0792 & -0.0935 & -0.1176 & -0.1374 & -0.1883 & -0.2101 & -0.2533 \\
$w$ (ANSYS) & -0.0443 & -0.0632 & -0.0797 & -0.0941 & -0.1185 & -0.1386 & -0.1904 & -0.2128 & -0.2572 \\
\hline
\end{tabular}

Table 12

Non-linear bending analysis $-\left(90^{\circ} / 0^{\circ}\right)-S=22.7$ - clamped-clamped

\begin{tabular}{llllllllll}
\hline$\left.F{ }^{*} 1 \mathrm{e} 6 \mathrm{~N}\right)$ & 2 & 5 & 7 & 10 & 12 & 13 & 14 & 15 \\
\hline$w$ SinRef-c & -0.06793 & -0.1339 & -0.1641 & -0.1993 & -0.2187 & -0.2275 & -0.2358 & -0.2436 & -0.2583 \\
$w$ (ANSYS) & -0.0680 & -0.1348 & -0.1656 & -0.2016 & -0.2215 & -0.2305 & -0.2391 & -0.2472 & -0.2623 \\
\hline
\end{tabular}




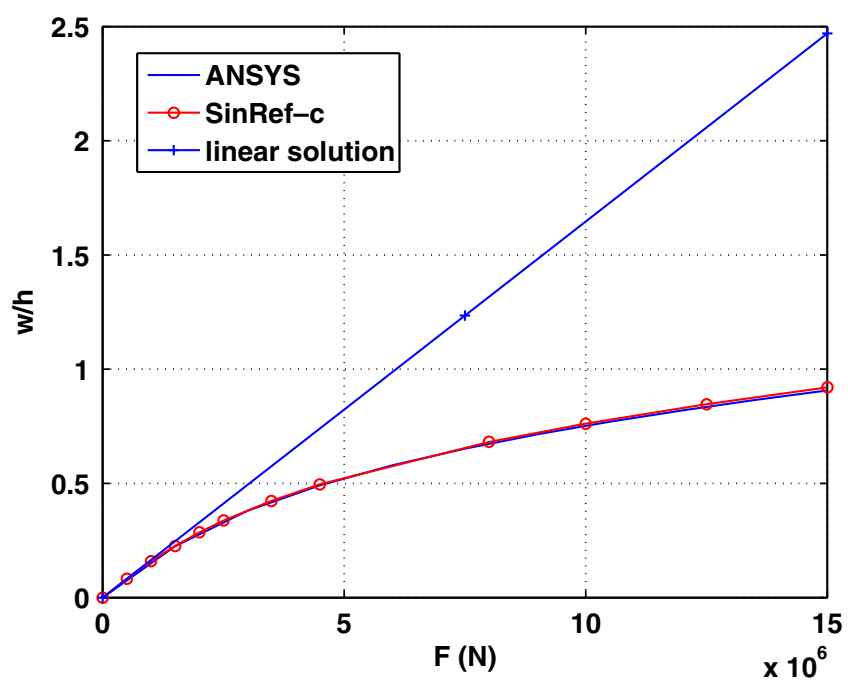

Fig. 7. $\bar{w} / F-$ three layers $\left(90^{\circ} / 0^{\circ} / 90^{\circ}\right)-S=22.7$ - clamped-clamped.

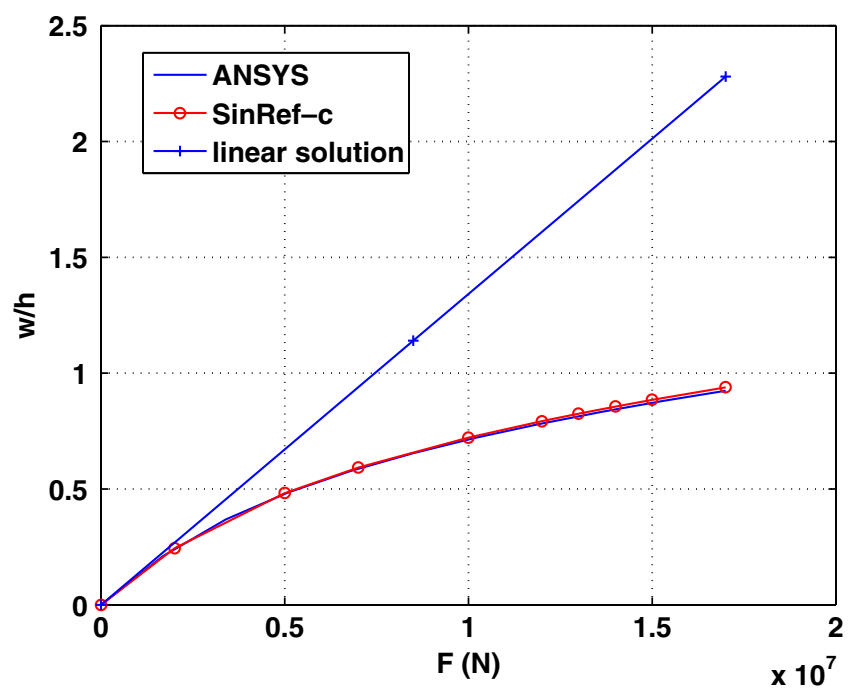

Fig. 8. $\bar{w} / F-$ two layers $\left(90^{\circ} / 0^{\circ}\right)-S=22.7$ - clamped-clamped. and laminated) beam finite element for linear and non-linear analyses. Based on sinus equivalent single layer model, a third-order kinematic per layer is added, improving the bending description for thick beams. There is no need for transverse shear correction factors and all the interface and boundary conditions are exactly satisfied. So, this approach has a strong physical meaning. Finally, the classical three unknown functions (two displacements, one rotation) are used and only one more function is needed in this new model. In fact, this finite element is simple and efficient for a low cost, compared to layerwise approach or plane elasticity model in commercial softwares.

Several numerical evaluations have proved that this model has very good properties in the field of finite elements. The convergence velocity is high and accurate results are obtained for thick or thin beams, all the boundary conditions, and different stacking sequences. Critical buckling loads and post-buckling are very well predicted.

This approach will be extended to plate and shell finite elements.

\section{Appendix A}

\section{A.1. Matrix $\left[A_{e}\left(\overrightarrow{\bar{u}}^{h}\right)\right]$}

According to the expression of the generalized strain vector $\left[\mathcal{E}_{e}^{h}\right]$ (see Eq. (19)), this matrix is written in the form:

$$
\left[A_{e}\left(\overrightarrow{\vec{u}}^{h}\right)\right]=\int_{\Omega}\left[\begin{array}{cccccc}
{[0]} & {[a 1]} & {[0]} & {[0]} & {[0]} & {[0]} \\
& {[a 2]} & {[0]} & {[a 3]} & {[0]} & {[a 4]} \\
& & {[0]} & {[0]} & {[0]} & {[0]} \\
& & & {[0]} & {[0]} & {[0]} \\
& \text { sym. } & & & {[0]} & {[0]} \\
& & & & & {[0]}
\end{array}\right] \mathrm{d} \Omega
$$

where, in the case of orthotropic layers, non zero terms of the sub-matrices have the following values:

$$
\begin{aligned}
& {[a 1]=\left[\begin{array}{ll}
\bar{C}_{11}^{(k)} \bar{u}_{3,1} & 0
\end{array}\right] \quad[a 2]=\left[\begin{array}{cc}
\bar{C}_{11}^{(k)} \bar{u}_{3,1}^{2} & \bar{C}_{11}^{(k)} \bar{u}_{3,1}\left(-z+f(z)+S_{\beta}(z)\right) \\
\bar{C}_{11}^{(k)} \bar{u}_{3,1}\left(-z+f(z)+S_{\beta}(z)\right) & 0
\end{array}\right]} \\
& {[a 3]^{\mathrm{T}}=\left[\begin{array}{ll}
\bar{C}_{11}^{(k)} \bar{u}_{3,1}\left(f(z)+S_{\beta}(z)\right) & 0
\end{array}\right] \quad[a 4]^{\mathrm{T}}=\left[\begin{array}{ll}
\bar{C}_{11}^{(k)} \bar{u}_{3,1} S_{\delta}(z) & 0
\end{array}\right]}
\end{aligned}
$$

the capability of our finite element to take into account the non-linearity. These Figures also indicate the robustness of the present finite element for geometrically non-linear tests.

\section{Conclusion}

In this article, a new numerical model, denoted SinRef-c, has been presented and evaluated through different non-linear benchmarks: buckling, post-buckling, and non-linear bending tests. It is a three-node multilayered (sandwich

\section{A.2. Matrix $\left[A_{e}\left(\bar{\sigma}^{h}\right)\right]$}

As above, we built this matrix in the form:

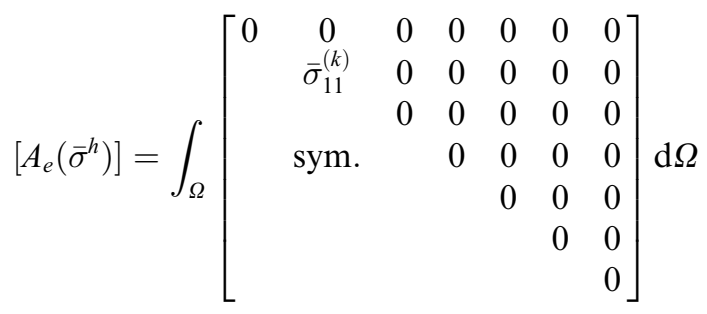




\section{References}

[1] Khdeir AA, Reddy JN. Buckling of cross-ply laminated beams with arbitrary boundary conditions. Compos Struct 1997;37:1-3.

[2] Vidal P, Polit O. A family of sinus finite elements for the analysis of rectangular laminated beams. Compos Struct 2008;84(1):56-72.

[3] Tanigawa Y, Murakami H, Ootao Y. Transient thermal stress analysis of a laminated composite beam. J Thermal Stresses 1989;12:25-39.

[4] Lee C-Y, Liu D, Lu X. Static and vibration analysis of laminated composite beams with an interlaminar shear stress continuity theory. Int J Num Meth Eng 1992;33:409-24.

[5] Soldatos KP, Elishakoff I. A transverse shear and normal deformable orthotropic beam theory. J Sound Vibr 1992;155(3):528-33.

[6] Reddy JN. A simple higher-order theory for laminated composite plates. J Appl Mech ASME 1984;51(4):745-52.

[7] Marur SR, Kant T. On the performance of higher order theories for transient dynamic analysis of sandwich and composite beams. Comput Struct 1997;65(5):741-59.

[8] Liu S, Soldatos KP. On the prediction improvement of transverse stress distributions in cross-ply laminated beams: advanced versus conventional beam modelling. Int J Mech Sci 2002;44:287-304.

[9] Murthy MVVS, Roy Mahapatra D, Badarinarayana K, Gopalakrishnan S. A refined higher order finite element for asymmetric composite beams. Compos Struct 2005;67(1):27-35.

[10] Subramanian P. Dynamic analysis of laminated composite beams using higher order theories and finite elements. Compos Struct 2006;73:342-53.

[11] Vinayak RU, Prathap G, Naganarayana BP. Beam elements based on a higher order theory - I. Formulation and analysis of performance. Comput Struct 1996;58(4):775-89.

[12] Matsunaga H. Interlaminar stress analysis of laminated composite beams according to global higher-order deformation theories. Comput Struct 2002;55(1):105-14.

[13] Ramos Loja MA, Barbosa JI, Mota Soares CM. Buckling behaviour of laminated beam structures using a higher-order discrete model. Compos Struct 1997;38:119-31.

[14] Karama M, Afaq KS, Mistou S. Mechanical behaviour of laminated composite beam by the new multi-layered laminated composite structures model with transverse shear stress continuity. Int J Solids Struct 2003;40:1525-46.

[15] Karama M, Abou Harb B, Mistou S, Caperaa S. Bending, buckling and free vibration of laminated composite with a transverse shear stress continuity model. Composite Part B: Eng J 1998;29:223-34.

[16] Matsunaga H. Vibration and buckling of multilayered composite beams according to higher order deformation theories. J Sound Vibr 2001;246(1):47-62.

[17] Song SJ, Waas AM. Effects of shear deformation on buckling and free vibration of laminated composite beams. Compos Struct 1997;37(1):33-43.

[18] Aydogdu M. Buckling analysis of cross-ply laminated beams with general boundary conditions by Ritz method. Compos Sci Technol 2006;66:1248-55.

[19] Chandrashekhara K, Bangera KM. Linear and geometrically nonlinear analysis of composite beams under transverse loading. Compos Sci Technol 1993;47:339-47.

[20] Polit O, Touratier M. High order triangular sandwich plate finite element for linear and nonlinear analyses. Comput Meth Appl Mech Eng 2000;185:305-24.

[21] Noor AK, Burton WS. Stress and free vibration analysis of multilayered composite plates. Comput Struct 1989;11(3):183-204.

[22] Carrera E. Layer-wise mixed models for accurate vibrations analysis of multilayered plates. J Appl Mech ASME 1998;65:820-8.

[23] Reddy JN. On refined computational models of composite laminates. Int J Num Meth Eng 1989;27:361-82.

[24] Karger L, Wetzel A, Rolfes R, Rohwer K. A three-layered sandwich element with improved transverse shear stiffness and stresses based on FSDT. Comput Struct 2006;84:843-54.
[25] Pagano NJ. Exact solutions for composite laminates in cylindrical bending. J Comp Mater 1969;3:398-411.

[26] Murakami H. Laminated composite plate theory with improved inplane responses. J Appl Mech ASME 1986;53:661-6.

[27] Reddy JN. A generalisation of two-dimensional theories of laminated composite plates. Commun Appl Numer Meth 1987;3:173-80.

[28] Icardi U. Higher-order zig-zag model for analysis of thick composite beams with inclusion of transverse normal stress and sublaminates approximations. Composite Part B: Eng J 2001;32:342-54.

[29] Di Sciuva M, Icardi U. Numerical assessment of the core deformability effect on the behavior of sandwich beams. Compos Struct 2001;52:41-53.

[30] Averill RC, Yip YC. Development of simple, robust finite elements based on refined theories for thick laminated beams. Compos Struct 1996;59:529-46.

[31] Cho Y-B, Averill RC. An improved theory and finite element model for laminated composite and sandwich beams using first-order zig-zag sublaminate approximations. Compos Struct 1997;37(3-4):281-98.

[32] Carrera E. On the use of the Murakami's zig-zag function in the modeling of layered plates and shells. Comput Struct 2004;82:541-54.

[33] Carrera E. Historical review of zig-zag theories for multilayered plates and shells. Appl Mech Rev 2003;56(3):287-308.

[34] Kapuria S, Dumir PC, Jain NK. Assessment of zigzag theory for static loading, buckling, free and forced response of composite and sandwich beams. Compos Struct 2004;64:317-27.

[35] Noor AK, Burton WS. Assessment of computational models for multilayered composite shells. Appl Mech Rev 1990;43(4):67-97.

[36] Reddy JN. Mechanics of laminated composite plates - theory and analysis. CRC Press Inc.; 1997.

[37] Carrera E. Theories and finite elements for multilayered, anisotropic, composite plates and shells. Arch Comput Meth Eng 2002;9:87-140.

[38] Kapania RK, Raciti S. Recent advances in analysis of laminated beams and plates. Part I: shear effects and buckling. AIAA J 1989;27:923-34.

[39] Touratier M. A generalization of shear deformation theories for axisymmetric multilayered shells. Int J Solids Struct 1992;29:1379-99.

[40] Ganapathi M, Patel BP, Polit O, Touratier M. A C $C^{1}$ finite element including transverse shear and torsion warping for rectangular sandwich beams. Int J Num Meth Eng 1999;45:47-75.

[41] Li X, Liu D. Generalized laminate theories based on double superposition hypothesis. Int J Num Meth Eng 1997;40:1197-212.

[42] Touratier M. An efficient standard plate theory. Int J Eng Sci 1991;29:901-16.

[43] Dau F, Polit O, Touratier M. $C^{1}$ plate and shell finite elements for geometrically nonlinear analysis of multilayered structures. Comput Struct 2006;84:1264-74.

[44] Touratier M. A refined theory of laminated shallow shells. Int J Solids Struct 1992;29(11):1401-15.

[45] Vidal P, Polit O. A thermomechanical finite element for the analysis of rectangular laminated beams. Finite Elem Anal Des 2006;42(10):868-83.

[46] Sze KY, Chen R, Cheung YK. Finite element model with continuous transverse shear stress for composite laminates in cylindrical bending. Finite Elem Anal Des 1998;31:153-64.

[47] Wu Z, Chen R, Chen W. Refined laminated composite plate element based on global-local higher-order shear deformation theory. Compos Struct 2005;70(2):135-52.

[48] Polit O, Touratier M, Lory P. A new eight-node quadrilateral shearbending plate finite element. Int J Num Meth Eng 1994;37:387-411.

[49] Wennerstrom H, Backlund J. Static, free vibration and buckling analysis of sandwich beams. Report 86-3, Department of Aeronautical Structures and Materials. Royal Institute of Technology, Stockholm, Sweden, 1986.

[50] Bhimaraddi A, Chandrashekhara K. Some observations on the modelling of laminated composite beams with general lay-ups. Compos Struct 1991;19:371-80.

[51] Ansys. Ansys theoretical manual. Swanson Analysis Inc.; 1986. 